\title{
ANTIOXIDANTES UTILIZADOS PARA COMBATER O ENVELHECIMENTO CUTÂNEO
}

\author{
Diego de Lima Pacheco' \\ Lívia Cabral Lobo ${ }^{2}$
}

RESUMO: A maioria da população sofre com o envelhecimento, com isso é de extrema importância saber o que devemos fazer para prevenir isso. A pele além de ser o maior órgão do nosso corpo e, também o mais exposto ao meio ambiente. Ela é composta por três camadas, que são à epiderme, derme e a hipoderme. O envelhecimento da pele é constituído por dois processos, que são chamados de envelhecimento intrínseco e o envelhecimento extrínseco. Destacando-se algumas das vitaminas que combatem o excesso de radicais livres que ajudam na manutenção das células, prevenindo-se do envelhecimento cutâneo. Neste resumo foi sinalizado com a importância de cuidar e auxiliar na alimentação adequada com o objetivo de prevenção do envelhecimento da pele.

Palavras-chaves: Envelhecimento cutâneo. Antioxidantes. Radicais livres.

ABSTRACT: The majority of the population suffers from aging, so it is extremely important to know what we should do to prevent it. The skin is not only the largest organ in our body, but also the most exposed to the environment. It is composed of three layers, which are the epidermis, dermis and hypodermis. Skin aging is made up of two processes, which are called intrinsic aging and extrinsic aging. Highlighting some of the vitamins that fight excess free radicals that help maintain cells, preventing skin aging. In this summary, the importance of caring for and assisting in proper nutrition was highlighted in order to prevent skin aging.

Keywords: Skin aging. Antioxidants. Free radicals.

\section{INTRODUÇÃO}

A população idosa tem aumentado em todo o mundo e até 2050 o número de pessoas com idade acima de 60 anos ou mais poderá chegar a 2 milhões, aproximadamente um quinto da população do planeta (ONU). A maioria dos países tem apresentado como característica demográfica, o envelhecimento populacional. No entanto, essa característica,

\footnotetext{
${ }^{\mathrm{I}}$ UNIG - Universidade Iguaçu, Curso de Graduação em Farmácia, Nova Iguaçu - RJ - Brasil.

${ }^{2}$ Orientadora: Msc. em Ciências de Tecnologia de Processos Químicos e Bioquímicos pela Universidade Federal do Rio de Janeiro (UFRJ). Professora assistente no Departamento de Farmácia da Universidade Iguaçu (UNIG).
} 
relaciona-se não apenas a longevidade, mas, também influencia no que diz respeito à saúde e qualidade de vida dessa população específica (MARI, 2016).

O número de idosos ( $\geq 60$ anos de idade) no Brasil, passou de 3 milhões em 1960, para 7 milhões em 1975 e 14 milhões em 2002 (aumento de 400\% em 40 anos), e deverá alcançar 32 milhões em 2020 (VERAS; OLIVEIRA, 2018).

Porém, a forma como se envelhece tem preocupado muitas pessoas, pois já não basta viver mais, é necessário viver com qualidade de vida, física e mental. Assim, a busca por meios e, mais especificamente, substâncias que favoreçam esse envelhecimento saudável tem impulsionado novas pesquisas (RUIVO; FRANCISCO; FIGUEIRAS, 2015).

Além de haver preocupações em relação à saúde física e ao bem-estar, existe também a preocupação com o envelhecimento cutâneo, pois cada vez mais a população deseja envelhecer sem apresentar as marcas dos anos vividos, e busca por métodos de intervenção para retardar ao máximo as marcas de envelhecimento (DECCACHE; SANTOS; SOUZA, 2006).

O envelhecimento é um processo a que todo ser vivo está sujeito com o avançar da idade, tendo como consequências diversas alterações que podem ser perceptíveis ou não (SCOTTI, 2003).

Existem diversas teorias que explicam os fatores do envelhecimento, dentre estas explicações está à ação dos Radicais Livres. As substâncias que combatem os Radicais Livres são chamadas antioxidantes e podem ser fornecidos através da dieta rica em frutas e vegetais ou ainda pela administração oral ou tópica. Somente o uso tópico e capaz de garantir níveis farmacológicos ideais para a pele (CAMPOS, 20II).

$\mathrm{Na}$ pele, o envelhecimento ocorre por acúmulo de danos moleculares nas células epiteliais, existindo dois processos que podem ocasioná-lo: o envelhecimento intrínseco e o envelhecimento extrínseco. O primeiro da natureza genética, tendo como exemplo mudanças hormonais associadas à menopausa. O segundo ocorre por acúmulos de danos ao DNA, causados por exposições excessivas aos raios solares ultravioletas e fatores ambientais como poluição, fumo, consumo excessivo de álcool e estresse (BARROS, 2012).

A pele tem papel importante na autoestima, nas relações sociais e na qualidade de vida do ser humano (SCOTTI, 2003). Trata-se de uma revisão realizada com base em livros, monografias, artigos da revista SciElo, evidências da utilização da ação das vitaminas, além de explicar o grande aumento de interesse populacional em prevenir-se do enve- 
lhecimento cutâneo, e também uma alimentação saudável abundante de vitaminas antioxidantes.

\section{2-OBJETIVOS}

\section{I - OBJETIVO GERAL}

Discutir a ação de algumas vitaminas antioxidantes, para combater o envelhecimento cutâneo.

\section{2 - Objetivo Específicos}

Revisar na literatura evidências sobre:

- Aumento de interesse populacional por cosméticos;

- Testes clínicos e laboratoriais demonstraram fortes evidências que as vitaminas assumem importantes funções na proteção;

- Administração oral e tópica de vitaminas;

- Os efeitos que os radicais livres na pele;

- Alimentação saudável abundante de antioxidantes.

\section{3- Metodologia}

O estudo realizado é de uma pesquisa de monografias, bibliografias e artigos disponíveis em meio eletrônico, sendo ressaltado as vitaminas antioxidantes, radicais livres, nutrientes e sua influência no combate ao envelhecimento cutâneo. Trata-se de uma pesquisa de caráter exploratório e descritivo.

\section{4 - Justificativa}

Hoje em dia, a preocupação com relação à alimentação saudável e cuidados estéticos está crescendo consideravelmente no mundo todo, tendo em vista que grande parte da população está à procura de melhor qualidade de vida e retardo de sinais de envelhecimento, onde estes fatores estão ligados diretamente na autoestima de ser humana. O envelhecimento da pele é um acontecimento natural, que pode ser postergado ou prevenido com hábitos de vida saudáveis aliados a uma dieta adequada composta por frutas, hortaliças e alimentos que ofereçam os nutrientes e antioxidantes necessários (SANTOS; OLIVEI$\mathrm{RA}, 2014)$. 


\section{5- DESENVOLVIMENTO}

\section{PELE}

A pele é o maior sistema orgânico do corpo humano, constitui em uma barreira protetora do organismo contra agressões do meio ambiente externo, ela é dividida em três camadas: epiderme, derme e hipoderme (PERSSONELLE, 2004; SCOTTI; VELASCO, 2003).

Sobre a composição da pele é importante destacar que 70\% de sua composição se dá na forma de água, sais minerais, proteínas, lipídios e glicídios. A pele desempenha várias funções, dentre elas estão: proteção, sensibilidade, termo regulação, função de secreção, absorção, respiração, reserva de lipídeos, produção de vitamina $\mathrm{D}$, cicatrização e função imunitária. Ela também é imediatamente visualizada, por isso sua integridade tem grande importância psicológica, fisiológica e social, pois influencia na aparência, afetando a autoestima, e podendo até interferir no convívio do indivíduo com toda sociedade (STRUTZEL et al., 2007; PERSONELLE, 2004; SCOTTI; VELASCO, 2003).

A pele é um órgão especial e peculiar, que com o tempo, apresenta leve desgaste na-

tural, porém é muito afetada pela radiação ultravioleta. A prevenção do envelhecimento pode ser feita através da proteção da pele dos raios solares, com filtros solares, captação dos radicais livres através da atuação celular das vitaminas antioxidantes e é a melhor atitude em relação a alterações do envelhecimento (STEINER, 2004).

$\mathrm{Na}$ pele, o envelhecimento se dá pelo acúmulo de danos moleculares nas células epiteliais, ocasionado por dois processos: envelhecimento intrínseco considerado de natureza genética, como por exemplo, a menopausa associada a mudanças hormonais. $\mathrm{O}$ extrínseco ocorre pelo acúmulo de danos ao DNA, devido à uma excessiva exposição solar, e fatores de natureza ambiental como fumo, poluição, estresse e consumo excessivo de álcool (VIEIRA et al., 2011).

As lesões causadas pelos radicais livres são inibidas por agentes antioxidantes nas células, dentre eles podemos citar vitaminas como, o retinol, o ácido ascórbico e o tocoferol, conhecidas pela nomenclatura, respectivamente, como vitamina $\mathrm{A}$, vitamina $\mathrm{C}$ e vitamina E (SANTOS et al., 2014). 
O tecido tegumentar (Figura I) é formado por tecidos de origem ectodérmica e mesodérmica que se superpõe, a partir da superfície, em três estruturas distintas, a epiderme, a derme e a hipoderme, esta última não é considerada por muitos autores como parte integrante da pele, embora seja estudada dentro do sistema tegumentar (KEDE; SABATOVICH, 2009).

A epiderme é a camada mais superficial da pele. Ela é muito importante do ponto de vista cosmético, pois é essa camada que dá à pele sua textura e umidade e contribui para sua cor. As camadas da epiderme recebem suas denominações de acordo com suas características típicas (BAUMANN; LESLIE, 2004).

A derme é subdividida em dois componentes, que são a porção papilar e a porção reticular. O limite entre elas é dado pelo plexo vascular superficial, que se situa um pouco abaixo da base dos cones epidérmicos (BAUMANN; LESLIE, 2004).

A derme, composta por elementos celulares e acelulares, é a camada que contém as fibras colágenas e elásticas, e a diminuição na produção destes elementos, ocorre a formação das rugas, é bastante vascularizada e contém terminações nervosas (TAMURA; ODO, 2010)

Os fibroblastos são os principais tipos celulares da derme e que produzem colágeno, elastina, outras proteínas da matriz e enzimas como colagenase (BAUMANN; LESLIE, 2004).

Como cofatores de reações enzimáticas, as vitaminas são substâncias orgânicas essenciais para a conservação das funções metabólicas dos seres vivos. Os antioxidantes provenientes da dieta são indispensáveis para defesa adequada contra oxidação, logo, tem importante papel na preservação da saúde. Crer-se que parte do efeito benéfico de uma dieta rica em frutas e vegetais se dá à variedade de antioxidantes vegetais, que podem atuar como suplementos benéficos para o ser humano. Eles previnem os danos provocados pelos radicais livres, disponibilizando o elétron ausente em suas moléculas. Desse modo, o radical livre consolida-se, não rompendo os elétrons de outras células (SANTOS et al., 2014).

Alimentos com propriedades nutricionais benéficas para o corpo humano são ditos alimentos funcionais, que auxiliam na manutenção da saúde, reduzindo o número de di- 
versas doenças. Compostos por combinações químicas complexas, tais alimentos, ao entrarem na célula pelo processo de nutrição, ditam sua atividade alterando sua composição. Estudos mostram atividades antioxidantes em frutas, verduras, grãos, óleos e legumes, tornando-os grandes aliados do retardamento do envelhecimento cutâneo, entretanto, é preciso observar o preparo correto do alimento e sua quantidade para que o efeito antioxidante seja adquirido na dose certa, para evitar reações adversas (ROCHA et al., 2016).

\section{ESQUEMA DE UM CORTE DE PELE}

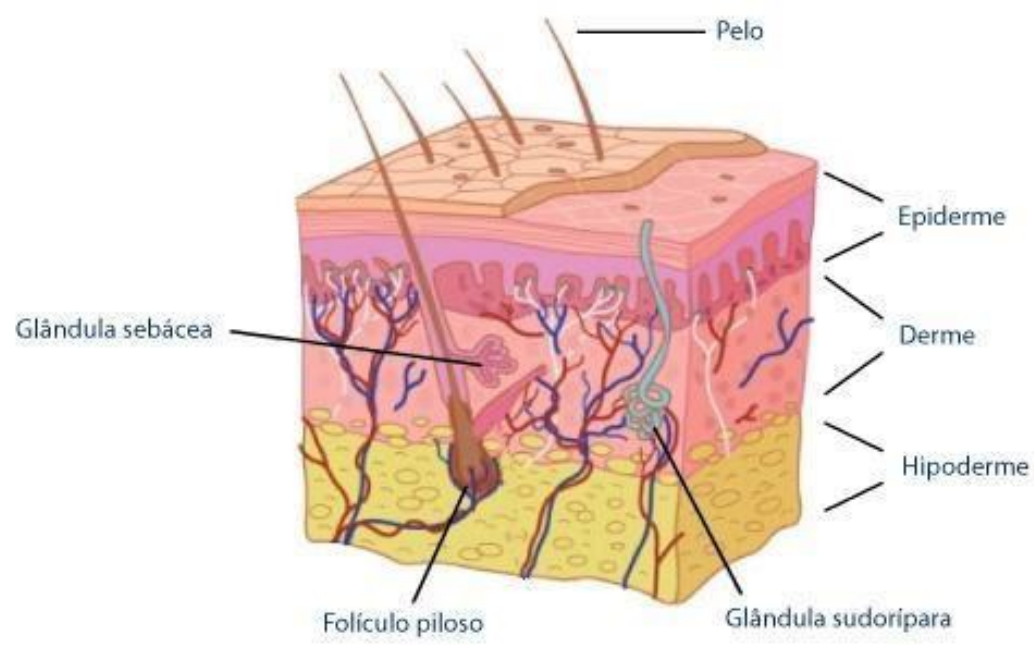

Figura I: Esquema da pele: epiderme, derme e hipoderme.

Fonte: dermatologia.net/a-pele.

O envelhecimento da pele, assim como de todo o organismo, também é resultado das alterações da derme. $\mathrm{O}$ dano às fibras colágenas está estreitamente envolvido nesse contexto. Os fibroblastos são responsáveis pelo metabolismo do colágeno, sintetizando colágeno tipo I, importante componente da matriz extracelular. Com a idade, ocorre desorganização no metabolismo do colágeno, diminuindo, assim, sua produção e aumentando sua degradação (MONTAGNER; COSTA, 2009).

$\mathrm{Na}$ pele, ao longo do tempo e com a diminuição da capacidade do organismo se restabelecer da ação dos radicais livres, os queratinócitos epidérmicos perdem propriedades adesivas, acarretando o afinamento epidérmico e ressecamento. Os fibroblastos da derme (colágeno e elastina) são agredidos do mesmo modo. Com isso ocorre uma reação global que abrange desde o desenvolvimento de rugas, perda da luminosidade, manchas, perda da 
elasticidade e da firmeza cutânea com isso, a flacidez, ressecamento da pele e perda do viço e, desenvolvimento de câncer nos casos mais sérios (FRIES et al., 2010).

\section{ENVELHECIMENTO}

Como havia destacado na introdução a dois tipos de envelhecimento, o intrínseco e o extrínseco. O intrínseco é um processo degenerativo, geneticamente controlado e caracterizado pelo decréscimo da capacidade funcional, diminuição da renovação celular, comprometimento do fluxo sanguíneo e redução das respostas imunológicas, deixando o organismo mais suscetível a doenças e morte celular. É responsável também pela redução de elastina levando à atrofia, ao ressecamento e à formação de rugas (VIEIRA, 2007; SCOTTI; VELASCO, 2003).

Com o avançar da idade a proliferação das células fica reduzida, consequentemente, a função dos fibroblastos é diminuída comprometendo a síntese e atividades de proteínas como o colágeno e a elastina, que conferem elasticidade e resistência à pele (VIEIRA, 2007; SCOTTI; VELASCO, 2003).

Mais agressivo e danoso o envelhecimento extrínseco também conhecido como foto envelhecimento, está relacionado a fatores ambientais como poluição, tabagismo, alcoolismo e pela indução dos raios UV por excessiva exposição solar, a pele se apresenta seca, espessa, amarelada, adelgada, flácida e com rugas profundas (SILVA et al., 20I6). Nesses dois processos ocorrem alterações no tecido cutâneo, como pode ser visto na Tabela I.

Tabela I. Alterações cutâneas provocadas por envelhecimento intrínseco e extrínseco.

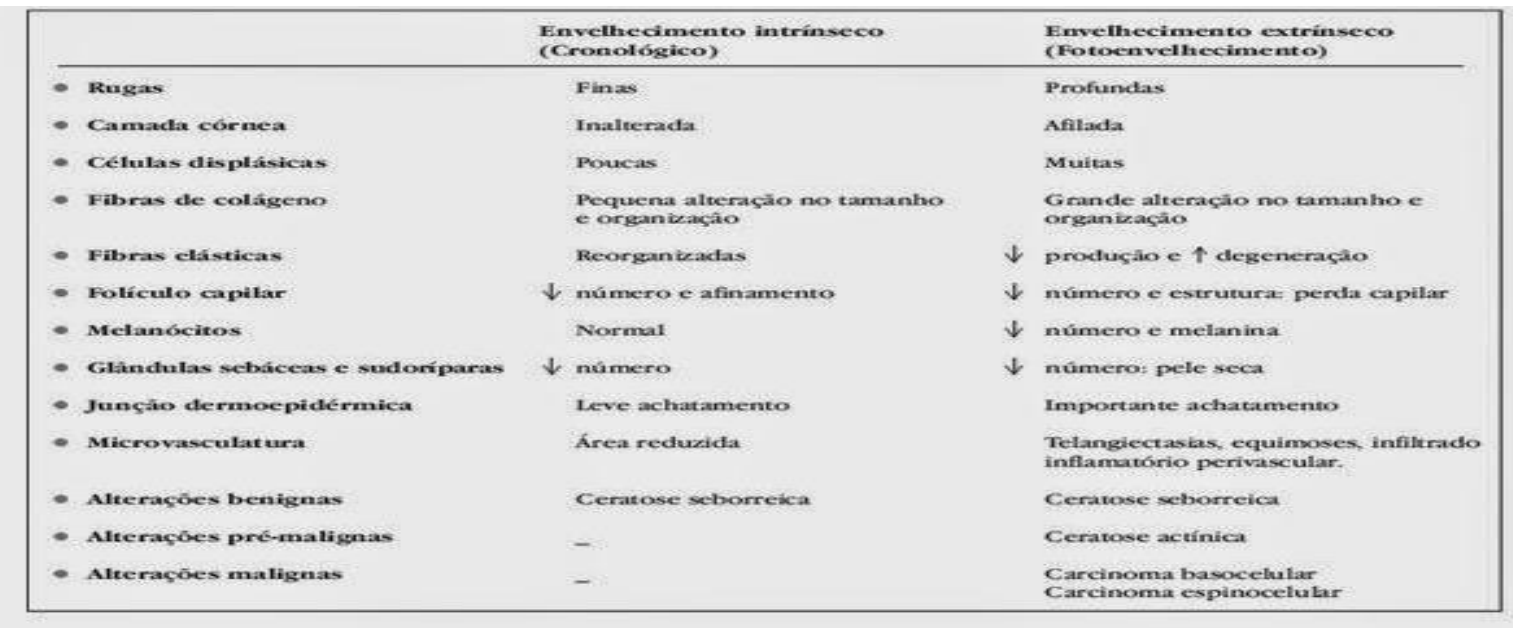

Fonte: $\mathrm{http://bioenvelhecimento.blogspot.com.br/2014/o6/fotoenvelhecimento.html}$ 


\section{RADICAIS LIVRES}

Os radicais livres são reconhecidos como uma das principais causas do envelhecimento e os primeiros estudos sobre eles surgiram por volta de 1924, mas só a partir dos anos 70 apareceram trabalhos, relatando a importância dos radicais livres para os seres humanos (SCOTTI; VELASCO, 2003; VANUCCHI et al., 1998).

Os radicais livres podem ser gerados no citoplasma, nas mitocôndrias ou na membrana e o seu alvo celular (proteínas, lipídeos, carboidratos e DNA) está relacionado com o seu sítio de formação. A geração de radicais livres é um processo contínuo e fisiológico, cumprindo funções biologicamente relevantes (BARBOSA et al., 2010; BIANCHI, 1999; VANUCCHI et al., 1998).

$\mathrm{Na}$ tentativa de obter estabilidade (Figura 2), quando não encontram nenhum outro RL para se ligar, eles captam elétrons de outras moléculas saudáveis. A molécula que perdeu os elétrons se transforma em outro radical livre, com isso, se inicia uma reação em cadeia que irá danificar muitas células. Caso não haja a intervenção dos antioxidantes, tal reação poderá ter caráter ilimitado. Este processo, chamado oxidação, provoca morte celular (SANTOS et al., 2014).

Figura 2. Formação dos radicais livres e a tentativa de equilíbrio dos antioxidantes.

\section{LIVRES, LEVES E PERIGOSOS}

Os radicais podem matar as células saudáveis

\section{Radical livre \\ Poluição, radiação solar e \\ o próprlo metabollsmo \\ liberam moléculas de \\ oxigēnio com um elêtron \\ solitário - o radical livre}

\section{Antioxidante}

Para se equilibrar, ele

"rouba" elétrons de outras

células. Os antioxidantes

"doam" um elétron ao

radical, neutralizando sua

atividade nociva

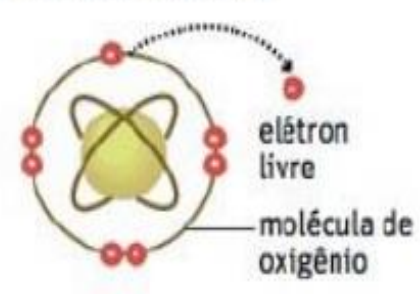

doaçăo de elétron

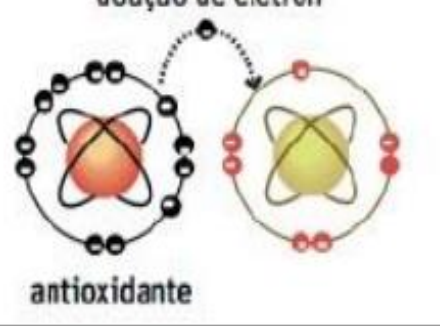

Fonte: VASCONCELOS, et al, 2014.

As principais fontes exógenas de radicais livres são alimentos ricos em gordura, álcool e ferro, fumo, radiação ultravioleta e o estresse, que produz aumento de catecolami- 
nas. Quando ocorre a formação de radicais livres em excesso provoca um desequilíbrio no balanço entre o processo oxidativo e o antioxidativo natural, ocorrerá um estresse oxidativo (KEDE; SABATOVICH, 2009).

O estresse oxidativo decorre de uma instabilidade entre a geração de compostos oxidantes e a atuação dos sistemas de defesa antioxidante. A geração de radicais livres ou espécies reativas não radicais é resultante do metabolismo de oxigênio. O sistema de defesa antioxidante tem a função de impossibilitar ou limitar os danos causados pela ação prejudicial dos radicais livres ou espécies reativas de não radicais (BARBOSA; COSTA; ALFENAS; DE PAULA; MINIM; BRESSAN, 20I0).

\section{VITAMINAS ANTIOXIDANTES}

As vitaminas são substâncias orgânicas essenciais para a manutenção das funções metabólicas dos seres humanos, elas atuam como cofatores de reações enzimáticas (MAHAN; SCOTT-STUMP, 1998).

Conforme Steiner (2002), a associação entre vitaminas e a saúde é conhecida há bastante tempo, porém, apenas recentemente se evidenciou sua eficácia no tratamento da pele. Testes clínicos e laboratoriais demonstraram fortes evidências que as vitaminas assumem importantes funções na proteção, correção e renovação da pele, além de assumir essas funções também nos cabelos e unhas. Antioxidantes são substâncias que, quando presente em pequenas concentrações comparadas com o substrato oxidável, retardam ou inibem de forma significativa a oxidação desse substrato, são agentes responsáveis pela 8 inibição e redução das lesões causadas pelos radicais livres nas células (DOLINSKY, 2009; BIANCHI, ANTUNES, 1999).

Os alimentos contêm compostos oxidantes, os quais podem ocorrer naturalmente ou ser introduzidos durante o processamento para o consumo (Waters et al., 1996). Por outro lado, os alimentos, principalmente as frutas, verduras e legumes (Tabela 2), também contêm agentes antioxidantes, tais como as vitaminas C, E e A, a clorofilina, os flavonóides, carotenóides, curcumina e outros que são capazes de restringir a propagação das reações em cadeia e as lesões induzidas pelos radicais livres (STAVRIC, 1994; FOTSIS et al., 1997; POOL-ZOBEL et al., 1997) 


\begin{tabular}{llll}
\hline Alimento & Antioxidante & Alimento & Antioxidante \\
\hline Mamão & - $\beta$-caroteno & Uva & -ácido elágico \\
Brócolis & -flavonóides & Salsa & -flavonóides \\
Laranja & - vitamina C & Morango & - vitamina C \\
Chá & - catequinas & Curry & - curcumina \\
Vinho & -quercetina & Noz & -polifenóis \\
Cenoura & - $\beta$-caroteno & espinafre & -clorofilina \\
Tomate & -carotenóides & Repolho & -taninos \\
\hline
\end{tabular}

Tabela 2. Algumas fontes de antioxidantes na dieta.

Fonte: https://www.scielo.br/j/rn/a/bzHBTqBfJr8jmJn3ZXxgnMs/?lang=pt

As vitaminas $C, E$ e o $\beta$-caroteno são consideradas excelentes antioxidantes, capazes de sequestrar os radicais livres com grande eficiência. $O$ uso de medicamentos, o tabagismo, as condições nutricionais, o consumo de álcool, a poluição do ar e outros fatores podem diminuir os níveis de antioxidantes celulares (Machlin, 1992; Roe, 1992). As defesas antioxidantes do organismo podem ser restabelecidas com dietas apropriadas e suplementos vitamínicos (CARAGAY, 1992; ANDERSON, 1996).

A vitamina $C$ é capaz de reduzir a vitamina E oxidada deixando-a novamente com ação antioxidante. No mesmo período, o tocoferol protege a membrana celular. O tocoferol é regenerado pelo ubiquinol ou ácido ascórbico e o ascorbil é restaurado pela glutationa reduzida, que é regenerada por grupamentos tióis (SANTOS et al., 2014).

A vitamina C (ácido ascórbico) é, geralmente, consumida em grandes doses pelos seres humanos, sendo adicionada a muitos produtos alimentares para inibir a formação de metabólitos nitrosos carcinogênicos. A vitamina $\mathrm{C}$ da dieta é absorvida de forma rápida e eficiente por um processo dependente de energia. O consumo de doses altas pode levar ao aumento da concentração dessa vitamina nos tecidos e no plasma sanguíneo. Os benefícios obtidos na utilização terapêutica da vitamina $\mathrm{C}$ em ensaios biológicos com animais incluem o efeito protetor contra os danos causados pela exposição às radiações e medicamentos (AMARA- MOKRANE et al., 1996).

Os estudos epidemiológicos também atribuem a essa vitamina um possível papel de proteção no desenvolvimento de tumores nos seres humanos (LUPULESCU, 1993; DUTHIE et al., 1996). Contudo, a recomendação de suplementação dessa vitamina deve ser 
avaliada especificamente para cada caso, pois existem muitos componentes orgânicos e inorgânicos nas células que podem modular a atividade da vitamina $C$, afetando sua ação antioxidante. A vitamina E é a principal vitamina lipossolúvel, podendo se apresentar em quatro formas: alfa, beta, gama e delta-tocoferol, e destas o alfa-tocoferol ou $\alpha$-tocoferol, é a forma biologicamente mais ativa e a mais estudada até o momento. Os tocoferóis transformam radicais livres em espécies mais estáveis por meio da doação de um átomo de hidrogênio, gerando produtos eletricamente estáveis ou menos reativos (CATANIA; BARROS; FERREIRA, 2009).

A vitamina $\mathrm{E}$ é um componente dos óleos vegetais encontrada na natureza em quatro formas diferentes $\alpha, \beta, \gamma$ e $\delta$-tocoferol, sendo o $\alpha$-tocoferol a forma antioxidante amplamente distribuída nos tecidos e no plasma. A vitamina E encontra-se em grande quantidade nos lipídeos, e evidências recentes sugerem que essa vitamina impede ou minimiza os danos provocados pelos radicais livres associados com doenças específicas, incluindo o câncer, artrite, catarata e o envelhecimento (MORRISSEY et al., 1994; HEINONEN et al., 1998).

A vitamina $E$ tem a capacidade de impedir a propagação das reações em cadeia induzidas pelos radicais livres nas membranas biológicas (Traber \& Packer, 1995). Os danos oxidativos podem ser inibidos pela ação antioxidante dessa vitamina, juntamente com a glutationa, a vitamina $\mathrm{C}$ e os carotenóides, constituindo um dos principais mecanismos da defesa endógena do organismo (RILEY, 1994).

A vitamina A é um fator importante no crescimento e na diferenciação celular. Além disso, tem apresentado ação preventiva no desenvolvimento de tumores da bexiga, mama, estômago e pele, em estudos realizados com animais. Estudos epidemiológicos também mostraram que o consumo regular de alimentos ricos em vitaminas $\mathrm{A}$ e $\mathrm{C}$ pode diminuir a incidência de câncer retal e de cólon. O $\beta$-caroteno, o mais importante precursor da vitamina A, está amplamente distribuído nos alimentos e possui ação antioxidante (RILEY, 1994).

A vitamina A foi a primeira vitamina lipossolúvel descoberta e o termo genérico para esta vitamina e seus derivados é retinóide (GUIRRO; GUIRRO, 2006). Esta vitamina é muito bem absorvida pela pele, atuando contra o espessamento e à pigmentação excessiva da pele. Facilitando a sua hidratação, combatendo os sinais de envelhecimento e a formação de radicais livres (TAMURA; ODO, 2010). A vitamina A é a forma genérica usada 
para descrever o retinol e todos os carotenóides que têm atividade biológica de trans retinol (GOMES; SAUNDERS; ACCIOLY, 2005).

Uma alimentação balanceada é indispensável para prevenção do envelhecimento cutâneo. É notório que a alimentação, quando constituída por excesso de gorduras saturadas, como frituras, embutidos, carnes gordas e outros, contribuem para o aumento dos radicais livres. Desse modo, há destruição das células saudáveis, podendo alterar a aparência da pele. Alimentos que englobam vitaminas e outras substâncias antioxidantes podem prevenir a ação destes radicais livres. Frutas, hortaliças, legumes e cereais integrais atuam, deste modo, impossibilitando que esses radicais destruam células saudáveis e aceleram o envelhecimento. Na Figura 5, mostramos alguns alimentos fontes de vitaminas antioxidantes (SANTOS et al., 2014).

VITAMINA

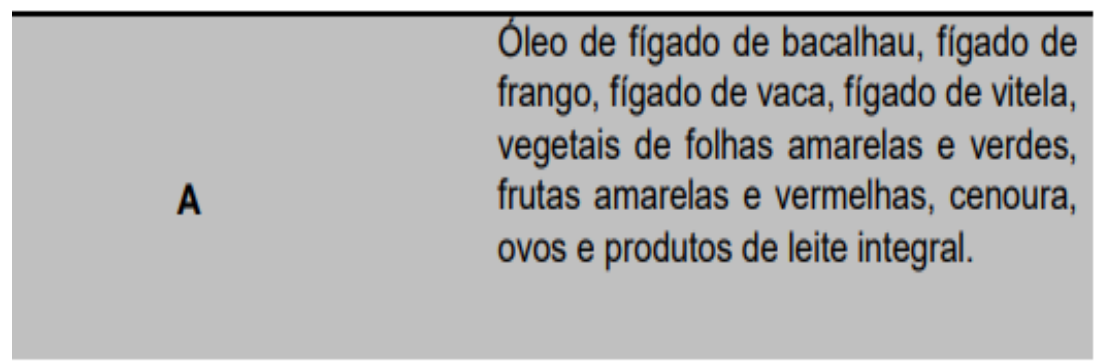

Frutas cítricas, acerola, laranja, caju, C goiaba, kiwi, limão, morango, brócolis, couve-flor, repolho.

Óleos vegetais, óleo de gérmen de E trigo, ovos, leite, fígado.

Figura 3. Vitaminas antioxidantes e suas principais fontes alimentares.

Fonte: SANTOS, et al., 2014.

O envelhecimento cutâneo é regulado tanto pela carga genética do indivíduo quanto pelo ambiente em que está inserido, principalmente pela exposição à luz solar, e pela deficiência nutricional, o que acelera ainda mais o processo biológico do envelhecimento (TESTON; NARDINO; PIVATO, 2017). 
Para manter uma pele saudável e rejuvenescida por mais tempo, é essencial a ingestão de alimentos com potencial antioxidante, entre os quais se destacam o alfa-tocoferol (vitamina E), beta-caroteno (pró-vitamina A), vitamina C, e compostos fenólicos, a destacar os Flavonoides e poliflavonoides, estes atuam prevenindo e removendo as espécies reativas que estão sendo produzidas em excesso, impedindo as lesões oxidativas e consequentemente o estresse oxidativo (CARVALHO et al., 2016).

\section{CONSIDERAÇÕES FINAIS}

O trabalho apresentado relata a extrema importância de cuidar da pele e da sua alimentação, além de ressaltar as agressões causadas pela exposição da pele com os raios UV. É fundamental também a importância de prevenir o envelhecimento cutâneo precoce, uma vez que é evidente que a sociedade atual possui uma incessante busca de aparentar em jovem por mais tempo, já que o fato de envelhecer pode ser assustador, fazendo com que as pessoas percam a sua autoestima.

\section{REFERÊNCIAS BIBLIOGRAFICAS}

AMARA-MOKRANE, Y.A; LEHUCHER-MICHEL, M.P; BALANSARD, G; DUMÉNIL, G; BOTTA, A. Protective effects of $\alpha$-hederin, chlorophyllin and ascorbic acid towards the induction of micronuclei by doxorubicin in cultured human lymphocytes. Mutagenesis, Oxford, v.II, n.2, p.I6I-167, 1996. Acesso em: I6 jun. 202I.

ANDERSON, D. Antioxidant defences against reactive oxygen species causing genetic and other damage. Mutation Research, Amsterdam, v.350, n.I, p.I03-108, 1996. Acesso em: 16 jun. 2021.

BARBOSA, Kiriaque Barra Ferreira; COSTA, Neuza Maria Brunoro; ALFENAS, Rita de Cássia Gonçalves; DE PAULA, Sérgio Oliveira; MINIM, Valéria Paula Rodrigues; BRESSAN, Josefina. Estresse oxidativo: conceito, implicações e fatores modulatórios. Rev. Nutr., Campinas, 23(4):629-643, jul./ago., 2010. Acesso em: 16 jun. 2021.

BARROS, C. M.; BOCK, P. M. Vitamina C na prevenção do envelhecimento cutâneo., 2012. Disponível em: 〈http://www.crn2.org.br/pdf/artigos/artigosi277237393.pdf〉 Acesso em: 15 jun. 202I.

BAUMANN, Leslie. Dermatologia Cosmética. Rio de Janeiro: Revinter, 2004. Acesso em: I6 jun. 2021.

BIANCHI, Maria de Lourdes; ANTUNES, Lusânia Maria Greggi. Radicais livres e os principais antioxidantes da dieta. Revista de Nutrição, Campinas, maio/ago., 1999. Disponível em: http://www.scielo.br/pdf/rn/vizn2/viznzaor.pdf. Acesso em: o3 jul. 202I. CAMPOS, J.S.; FRASSON, A.P.Z. Avaliação da atividade antioxidante do extrato aquo- 
so de Lafoensia pacari A. ST-HIL. em emulsão não-iônica. Revista Ciências Farmácia Básica Apl., 2011;32(3):363-368 ISSN 1808-4532. Acesso em: 15 jun. 2021.

CARAGAY, A.B. Cancer preventive foods and ingredients. Food Technology, Chicago, v.46, p.65-68, 1992. Acesso em: i6 jun. 2021.

CATANIA, Antonela Siqueira; BARROS, Camila Risso de; FERREIDA, Sandra Roberta G. Vitaminas e minerais com propriedades antioxidantes e risco cardiometabólico: controvérsias e perspectivas. Arquivos Brasileiros de Endocrinologia Metabólicos. 2009;53/5. Acesso em: I6 jun. 2021.

DOLINSKY, Manuela. Nutrição funcional. São Paulo: Roca, 2009. Acesso em: i6 jun. 2021.

FOTSIS, T. et al. Flavonoids, dietary-derived inhibitors of cell proliferation and in vitro angiogenesis. Cancer Research, Baltimore, v.57, n.14, p.2916-2921, 1997. Acesso em: 22 abr. 2021.

FRIES, A. T.; FRASSON, A. P. Z. Avaliação da atividade antioxidante de cosméticos anti-idade. Revista contexto e saúde, editora UNIJUİ, Ijuí, v. Io, n. 19, p. 17-23, 2010. Acesso em: I5 jun. 2021.

GOMES, Mirian Martins; SAUNDERS, Cláudia; ACCIOLY, Elizabeth. Papel da vitamina A na prevenção do estresse oxidativo em recém-nascidos. Revista Brasileira Saúde e Maternidade Infantil, Recife, 5 (3): 275-282, jul. / set., 2005. Acesso em: 22 abr. 202I.

HEINONEN, O.P.; ALBANES, D.; VIRTAMO, J.; TAYLOR, P.R.; HUTTUNEN, J.K.; HARTMAN, A.M.; HAAPAKOSKI, J.; MALILA, N.; RAUTALAHTI, M.; RIPATTI, S.; MAENPAA, H.; TEERENHOVI, L.; KOSS, L.; VIROLAINEN, M.; EDWARDS, B.K. Prostate cancer and supplementation with alpha-tocopherol and beta-carotene: incidence and mortality in controlled trial. Journal of the National Cancer Institute, Bethesda, v.9o, n.6, p.440-446, 1998. Acesso em: 22 mai. 2021.

KEDE, Maria; SABATOVICH, Oleg. Dermatologia Estética. São Paulo: Atheneu, 2009. Acesso em: 22 mai. 202I.

MONTAGNER, Suelen; COSTA, Adilson. Bases biomoleculares do fotoenvelhecimento. Anais Brasileiros de Dermatologia, 2009;84(3):263-9. Acesso em: 22 abr. 2021.

MORRISSEY, P.A.; SHEEHY, P.J.A.; GAYNOR, P. Vitamin E. American Journal of Clinical Nutrition, Bethesda, v.62, p.260-264, 1994. Acesso em: 22 abr. 2021.

PERSSONELLE, Jussara G. Cosmitraria: a ciência da beleza. Rio de Janeiro: Revinter, 2004. Acesso em: 22 mai. 2021.

POOL-ZOBEL, B.L.; BUB, A.; MÜLLER, H.; WOLLOWSKI, I.; RECHKEMMER, G. Consumption of vegetables reduces genetic damage in humans: first results of a human intervention trial with carotenoid--rich foods. Carcinogenesis, New York, v.18, n.9, p.18471850, 1997. Acesso em: 22 mai. 2021.

RILEY, P.A. Free radicals in biology: oxidative stress and the effects of ionizing radiation. International Journal of Radiation Biology, London, v.65, n.I, p.27-33, 1994. Acesso em: 22 mai. 2021. 
ROCHA, E. C.; SARTORI, C. A.; NAVARRO, F. F. A aplicação de alimentos antioxidantes na prevenção do envelhecimento cutâneo. Revista científica da 28 FHO/UNIARARAS, Rio Claro/SP, v. 4, n. I, p. 19-26, 2016. Acesso em: 22 abr. 2021.

SANTOS, M. P.; OLIVEIRA N. R. F. Ação das vitaminas antioxidantes na prevenção do envelhecimento cutâneo. Ciências da Saúde, Santa Maria, v. 15, n. I, p. 75-89, 2014. Acesso em: 22 abr. 202I.

SCOTTI, L.; VELASCO, M. V. R. Envelhecimento cutâneo à luz da cosmeotologia.São Paulo, Tecnopress, 2003. Acesso em: I5 jun. 2021.

SILVA, C. M.; SANTOS, R. A.; CAVALCANTE, C. F. E. Os benefícios da nutrição na prevenção do envelhecimento cutâneo. Revista conexão eletrônica, Três Lagoas/MS, v. I3, n. I, 2016. Acesso em: I2 abr. 2021.

STAVRIC, B. Antimutagens and anticarcinogens in foods. Food Chemical Toxicology, Oxford, v.32, n.I, p.79-9o, 1994. Acesso em: I2 abr. 2021.

STEINER, Denise. Tratamentos para o envelhecimento. Disponível em: http://www.denisesteiner.com.br/artigo_mes/tratamentos_evelhecimento.htm. Acesso em: 17 abr. 2021.

STRUTZEL, Elenir; CABELLO, Hérica; QUEIROZ, Lumena; FALCÃO, Mário Cícero. Análise dos fatores de risco para o envelhecimento da pele: aspectos gerais e nutricionais. Revista Brasileira de Nutrição Clínica. São Paulo, 2007 Disponível em: http://nutricore.com.br/app/webroot/img/bibliotecas/Analise\%2odos\%2ofatores \%20de\%2orisco\%2opara\%200\%2oenvelhecimento.pdf. Acesso em: is jun. 2021.

TAMURA, Bhertha M; ODO, Maria Y. Anatomia da face aplicada aos preenchedores e à toxina botulínica tipo A. Surg Cosmet Dermatol. Vol. 2(3), pag.195-204, 2010. Acesso em: 22 abr. 2021.

VANUCCHI, Helio; MOREIRA, Emilia AM; CUNHA, Daniel Ferreira; JUNQUEIRA-FRANCO, Márcia V. M.; BERNARDES, Mônica M.; JORDÃO JÚNIOR, Alceu A. Papel dos nutrientes na peroxidação lipídica e no sistema de defesa antioxidante. Revista da Faculdade de Medicina de Ribeirão Preto. São Paulo, 1998. Disponível em:

http://www.fmrp.usp.br/revista/1998/vol3InI/papel_nutrientes_peroxidacao_lipi dica.pdf. Acesso em: is jun. 2021

VIEIRA, A. C. Q. M.; MEDEIROS, L. A.; PALÁCIO, S. B.; LYRA, M. A. M.; ALVES, L. D. S.; ROLIM, L. A.; NETO, P. J. R. Fatores de crescimento: uma nova abordagem 29 cosmecêutica para o cuidado antienvelhecimento. Revista Brasileira de Farmácia, Recife/PE, v. 92, n. 3, p.80-89, 2011. Acesso em: 12 abr. 2021. 